\title{
3 Research Square

\section{Update on Prevalence of Diagnosed Systemic Lupus Erythematosus (SLE) by Major Health Insurance Types in the US}

\section{Yiting Wang ( $\square$ ywang28@its.jnj.com )}

Janssen Research and Development LLC https://orcid.org/0000-0002-9589-4494

Laura L Hester

Janssen Research and Development Titusville

Jennifer Lofland

Janssen Scientific Affairs LLC

Shawn Rose

Janssen Research and Development Spring House

Chetan S Karyekar

Janssen Scientific Affairs LLC

David M Kern

Janssen Research and Development Titusville

Margaret Blacketer

Janssen Research and Development Titusville

Kourtney Davis

Janssen Research and Development Titusville

Kimberly Shields-Tuttle

Janssen Research and Development Spring House

Research note

Keywords: Systemic lupus erythematosus, health insurance, prevalence, epidemiology

Posted Date: June 24th, 2021

DOl: https://doi.org/10.21203/rs.3.rs-645989/v1

License: (c) (i) This work is licensed under a Creative Commons Attribution 4.0 International License.

Read Full License 


\section{Abstract}

\section{Objective}

To provide current estimates of the number of patients with prevalent systemic lupus erythematosus (SLE) by major health insurance types in the US and describe patient characteristics. Four large US health insurance claims databases were analyzed to represent different types of insurance coverage, including private insurance, Medicaid, and Medicare Supplemental.

\section{Results}

Overall unadjusted SLE prevalence per 100,000 persons in the US ranged from 150.1 (private insurance) to 252.9 (Medicare Supplemental insurance). Extrapolating to the US civilian population in 2016, we estimated roughly 345,000 to 404,000 prevalent SLE patients with private/Medicare insurance, and 99,000 prevalent SLE patients with Medicaid insurance.

Comorbidities, including renal failure/dialysis were commonly observed across multiple organ systems in SLE patients (8.4-21.1\%).

We estimated a larger number of prevalent SLE cases in the US civilian population than previous reports and observed extensive disease burden based on a 1-year cross-sectional analysis.

\section{Introduction}

Systemic lupus erythematosus (SLE) is a complex autoimmune disease that can affect multiple body organs and systems, with prevalence previously reported in a broad range of populations from 6.5 to 178.0 per 100,000 worldwide, [1] and from 24 to 150 per 100,000 among adults in the US. [2] There are no current estimates of how many people in the US have SLE, although a commonly quoted estimate suggests a prevalence of 161,000 with definite SLE and 322,000 with definite or probable SLE. [3] This estimate was derived by projecting the SLE prevalence among persons aged 15 to 64 years in San Francisco Kaiser Foundation Health Plan in 1965-1973, [4] to the corresponding 2005 US population Census data. It is not known if the prevalence estimates from 50 years ago still hold today with increasing epidemiological surveillance and research, including the development of SLE classification criteria over time. [1] Having a current estimate of the number of prevalent SLE patients helps with understanding the disease burden and health care planning. In the US, private, Medicare and Medicaid insurance make up the major civilian health insurance sectors. [5] A recent study estimated that there were 97,590 people with prevalent SLE among the total Medicare population in 2016. [6] Other than a poster abstract that estimated a total of 313,436 prevalent SLE patients in the US in 2009 using private, Medicare and Medicaid insurance claims databases, [7] no current estimates of the number of prevalent SLE patients by insurance coverage was available in the public domain. 
In this report, we provide current estimates for SLE prevalence proportions and prevalent number of SLE patients in the US by major health insurance types. In addition, we describe 1-year cross-sectional SLE health care utilization and encounters across different insurance types.

\section{Main Text}

\section{Data sources}

We used four large US health insurance claims databases converted to the OMOP Common Data Model: [8] IBM MarketScan ${ }^{\circledR}$ Commercial (CCAE), IBM MarketScan ${ }^{\circledR}$ Medicare Supplemental (MDCR), Optum Deidentified Clinformatics ${ }^{\circledR}$ Data Mart Databases (Optum), and IBM MarketScan ${ }^{\circledR}$ Multi-state Medicaid (MDCD). CCAE represents data from individuals enrolled in US employer sponsored insurance health plans. The data includes health insurance claims (e.g., inpatient, outpatient, and outpatient pharmacy) as well as enrollment data from large employers and health plans who provide private health care coverage to employees, their spouses, and dependents. MDCR is an administrative health claims database for Medicare-eligible active and retired employees and their Medicare-eligible dependents from employer-sponsored supplemental plans. Persons under age 65 in MDCR had Medicare coverage due to disability (including from SLE), therefore were not considered as representative of the general US population, and were excluded from the analysis when projecting the number of prevalent SLE cases in the US below. Optum is an adjudicated administrative health claims database for members with private health insurance. The population is primarily representative of US commercial claims patients (0-65 years old) with some Medicare patients (65+ years old). MDCD is an administrative health claims database that contains the pooled healthcare experience of Medicaid enrollees, covered under fee-forservice and managed care plans from multiple states.

The use of Optum and MarketScan ${ }^{\circledR}$ databases was reviewed by the New England Institution Review Board (IRB) and was determined to be exempt from broad IRB approval, as this research project did not involve human subject research.

\section{Patients}

In each database, prevalent SLE cases were identified for calendar year 2016 based on having $\geq 1$ SLE diagnosis codes or $\geq 1$ belimumab prescription in 2016; and meeting at least one of the following conditions [9-13] before or during 2016: (1) $\geq 3$ SLE diagnoses spanning across $\geq 60$ days; or (2) $\geq 1$ belimumab infusion/injection and $\geq 2$ SLE diagnoses; or (3) $\geq 1$ inpatient SLE diagnosis and $\geq 1$ dispensed prescription for systemic corticosteroids, antimalarials, or immunomodulators commonly used in SLE treatment. At least one year of continuous enrollment in the health plan was required of all individuals. The study sample creation flowchart and detailed descriptions of the claims database algorithms for defining SLE from the published literature are provided in the Supplemental Materials. 


\section{Analysis}

In each database, age- and sex-specific SLE prevalence proportion was estimated for calendar year 2016. The numerator included diagnosed SLE cases and denominator included individuals enrolled for the entire year of 2016. Projection of prevalent SLE cases (rounded down to the nearest thousands) in the US was based on the age- and sex-specific prevalence proportions from each database multiplied by the corresponding US census population counts by age, sex, and insurance type, and taken the sum. [5] Given that CCAE (mostly people age 65 ) and MDCR (mostly people age 265 ) cover complementary age groups, we combined the estimated SLE prevalence proportions from MDCR age $\geq 65$ and CCAE age $<65$ to project to US civilian population with private insurance coverage of all ages. The estimated SLE prevalence proportions from Optum were used as a second source to project to US civilian population with private/Medicare insurance coverage across all ages. These two estimates (i.e., CCAE age $<65$ combined with MDCR age $\geq 65$, Optum) for people with private/Medicare insurance coverage were separately combined with the third projection, from MDCD to persons with Medicaid coverage, to estimate overall SLE prevalence in the US civilian population. To enable comparison with agestandardized SLE prevalence published previously from population-based SLE surveillance programs, we provided age-standardized SLE prevalence from these insurance databases (see Supplemental Table 2).

To provide a 1-year cross-sectional profile of disease burden in 2016, we also described the health care utilization and encounters for various conditions and comorbidities for SLE patients using prescription drug, procedure, and diagnosis codes from the insurance claims. All codes are provided in the Supplemental Materials.

\section{Results}

In 2016, a total of 28,848 (CCAE), 3,922 (MDCR age $\geq 65$ ), 23,877 (Optum) and 15,096 (MDCD) prevalent cases of SLE were identified. The unadjusted SLE prevalence per 100,000 persons was 150.1 (25.6 in males and 266.0 in females), 236.4 (66.1 in males and 372.7 in females), 195.4 (39.2 in males and 341.1 in females) and 158.7 (27.1 in males and 258.9 in females) in CCAE, MDCR age $\geq 65$, Optum, and MDCD, respectively. Age-standardized SLE prevalence per 100,000 persons was 134.9, 146.7, 143.3, and 244.3 in CCAE, MDCR age $\geq 65$, Optum, and MDCD, respectively (see Supplemental Materials for details).

The age and sex-specific prevalence proportions of each database were plotted in Figure 1. SLE prevalence in females was consistently higher than in males across all age groups in all four databases. Female to male ratio of SLE prevalence by age was provided in the Supplemental Figure 2. The projected numbers of prevalent SLE cases with private (including Medicare) or Medicaid insurance ranged from 444,000 (i.e., 345,000 with private/Medicare plus 99,000 with Medicaid insurance) to 503,000 (404,000 with private/Medicare plus 99,000 with Medicaid insurance) (Table 1).

Across the four databases, $15 \%$ to $33 \%$ of patients had at least one hospitalization in 2016 (Table 2). Healthcare utilization including hospitalizations for infections appeared highest, despite lowest mean age 
in MDCD. Comorbidities and SLE disease manifestations were common across multiple organ systems in SLE patients, including renal failure/dialysis that ranged from $8.4 \%$ (in CCAE) to $21.1 \%$ (MDCR). Across the four databases, SLE medications dispensed the most frequently were systemic corticosteroids (61$65 \%$ ) and anti-malarial drugs (35-63\%); anti-inflammatory biologic agents were infrequently prescribed $(<5 \%)$ in any of the database cohorts.

\section{Discussion}

Our study characterized patient cohorts from four large US insurance claims databases to provide updated estimates for SLE prevalence proportions and the number of SLE cases in the US civilian populations. The cross-sectional design of health care utilization and encounters during calendar year 2016 demonstrated considerable burden across all insurance types.

We estimated more prevalent SLE cases in the US than previous reports, including that based on prevalence proportions from 50 years ago applied to US population in 2005, [3] and an abstract using the same databases in 2009 [7]. This likely reflects both increased SLE prevalence proportions (compared with the 1970s, and with previous population-based surveillance studies shown in Supplemental Table 2) and overall increased US population size (compared with 2005, 2009). Rigorous algorithms were used to identify SLE cases [9-13], with an estimated sensitivity and specificity both $>90 \%$ and positive predictive value $80 \%-90 \%$ (Supplemental Table 1,3). Although chart validation was not feasible, the SLE algorithms reflected real-world health care experience and utilization for presumed SLE patients in routine clinical practice. For example, $98 \%$ to $99 \%$ of the cases across the four databases had $\geq 3$ SLE diagnoses spanning at least 60 days apart.

The strength of the study includes using data from large and differing representative U.S. healthcare claims databases standardized to a common data model [8] to provide updated estimates of SLE prevalence.

\section{Conclusion}

Overall, our research provides an update on the estimates of prevalent cases of SLE from a variety of US insurance types, each indicating a significant utilization burden. Future research is needed to understand the health care and societal costs for the management of persons diagnosed with SLE, including causes of health disparities, resulting disability and premature mortality among patients younger than 65 .

\section{Limitations}

First, the four databases do not cover persons without health insurance or all persons with health insurance in the US. Although about $50 \%$ of the US population covered by Medicare insurance have some supplemental private insurance, the MDCR database in our study includes persons covered by both Medicare and employer supplemental insurance, and may not be representative of the entire Medicare 
population at risk for SLE. For example, a recent study using a $20 \%$ random sample from US Medicare insurance estimated 54,490 persons aged $\geq 65$ had prevalent SLE in 2016. [6] The corresponding projection using the MDCR database in our study was 60,000 . Our estimate was only slightly higher, which may be explained by differences in the study populations as well as in the definitions of prevalent SLE between the two studies. Li and colleagues [6] defined prevalent SLE by requiring all the SLE criteria to be met in the cohort year 2016, whereas our study defined prevalent SLE by requiring all the SLE criteria to be met during or before 2016. Because of the flare/remission disease patterns of SLE, [14] our more sensitive definition could have captured prevalent SLE cases who happened to be inactive or in remission in 2016 and therefore may not have met the inclusion criteria applied by Li and colleagues. [6]

Another limitation of our study is that we could not identify persons overlapping with multiple insurance types from the four databases. Adding the projected SLE cases across different insurance types may overestimate the total number of SLE cases in the US. For example, Li and colleagues reported about $13 \%$ of SLE patients had dual Medicare and Medicaid coverage. [6] However, we expect the overlap between Medicare and Medicaid in CCAE and Optum to be lower given Medicare supplemental coverage. Finally, our study showed extensive health care utilization by SLE cases across the individual insurance types in calendar year 2016, especially for Medicaid.

\section{List Of Abbreviations}

SLE, systemic lupus erythematosus; US, United States; CCAE, IBM MarketScan ${ }^{\circledR}$ Commercial database; MDCR, IBM MarketScan ${ }^{\circledR}$ Medicare Supplemental database; Optum, Optum De-identified Clinformatics ${ }^{\circledR}$ Data Mart Databases; MDCD, IBM MarketScan ${ }^{\circledR}$ Multi-state Medicaid database.

\section{Declarations}

\section{Ethics approval (include appropriate approvals or waivers)}

This study used IBM ${ }^{\circledR}$ Marketscan ${ }^{\circledR}$ and Optum ${ }^{\circledR}$ retrospective administrative claims data. Data were de-identified and comply with the Health Insurance Portability and Accountability Act and the 1964 Helsinki Declaration and its later amendments or comparable ethical standards. The use of the IBM ${ }^{\circledR}$ Marketscan ${ }^{\circledR}$ and Optum ${ }^{\circledR}$ databases was reviewed by the New England Institution Review Board (IRB) and was determined to be exempt from broad IRB approval, as this research project did not involve human subject research. Informed consent was not obtained as this research project did not involve human subject.

\section{Consent to participate}

Not applicable. 


\section{Availability of data and material}

The data underlying this article were made available to the authors by third-party license from IBM MarketScan ${ }^{\circledR}$, and Optum ${ }^{\circledR}$, commercial data providers in the US. Under the licensing agreement, the authors cannot provide the raw data themselves. Other researchers could access the data by purchase through IBM MarketScan ${ }^{\circledR}$ and Optum ${ }^{\circledR}$; and the inclusion criteria specified in the Methods section would allow them to identify the same cohort of patients we used for these analyses.

\section{Code availability (software application or custom code)}

The common data model (CDM) methods are openly available from https://www.ohdsi.org/datastandardization/the-common-data-model/. Specific diagnosis and drug codes in the study are provided in the Supplemental Materials.

\section{Competing interests}

YW, LLH, CSK, DMK, MB, KD and KS are all current employees of Janssen Pharmaceutical companies; all authors were employees of Janssen Pharmaceutical companies at the time of this study, which was conducted as part of their employment.

\section{Funding}

This research received no specific grant from any funding agency in the public, commercial, or not-forprofit sectors.

\section{Authors' contributions}

$\mathrm{YW}, \mathrm{JL}, \mathrm{SR}$ and KS contributed to the conception of the study; all authors contributed to the design of the study; LLH, DMK, MB contributed to the acquisition of data and analysis; all authors contributed to the interpretation of data, drafting and revising the manuscript critically for important intellectual content; all authors approved of the version submitted.

\section{Acknowledgments}

The authors thank Dr. Tania González-Rivera for her consultations and inspirations for research in lupus; and thank Ms. Gayle Murray for her help with reviewing and preparing the manuscript.

\section{Consent for publication}




\section{Authors' Emails}

Yiting Wang, yiting-w@hotmail.com; Jennifer Lofland, jennifer.lofland@gmail.com; Sean Rose, srosemdphd@gmail.com; Chetan S. Karyekar, ckaryeka@its.jnj.com; David M. Kern,

DKern2@its.jnj.com; Margaret Blacketer, mblacke@its.jnj.com; Kourtney Davis, KDavis24@its.jnj.com ; Kimberly Shields-Tuttle, KShields@its.jnj.com.

\section{References}

1. Pons-Estel GJ, Ugarte-Gil MF, Alarcon GS. Epidemiology of systemic lupus erythematosus. Expert Rev Clin Immunol. 2017; 13: 799-814.

2. Feldman $\mathrm{CH}$, Hiraki LT, Liu J, et al. Epidemiology and sociodemographics of systemic lupus erythematosus and lupus nephritis among US adults with Medicaid coverage, 2000-2004. Arthritis Rheum. 2013; 65: 753-63.

3. Helmick CG, Felson DT, Lawrence RC, et al. Estimates of the prevalence of arthritis and other rheumatic conditions in the United States. Part I. Arthritis Rheum. 2008; 58: 15-25.

4. Fessel WJ. Systemic lupus erythematosus in the community. Incidence, prevalence, outcome, and first symptoms; the high prevalence in black women. Arch Intern Med. 1974; 134: 1027-35.

5. Barnett JC and Berchick ER. Current Population Reports, P60-260, Health Insurance Coverage in the United States: 2016. U.S. Government Printing Office; Washington, DC, 2017.

6. Li S, Gong T, Peng Y, et al. Prevalence and incidence of systemic lupus erythematosus and associated outcomes in the 2009-2016 US Medicare population. Lupus. 2020; 29: 15-26.

7. Gandhi K, Alemao E, Kawabata H, et al. Prevalence Of Systemic Lupus Erythematosus and Lupus Nephritis In The United States: Analysis Of Commercial and Public Insurance Billing Data. Arthritis \& Rheumatism. 2013;65(S10). S457.

8. Voss EA, Makadia R, Matcho A, et al. Feasibility and utility of applications of the common data model to multiple, disparate observational health databases. J Am Med Inform Assoc. 2015; 22: 553-64.

9. Barnado A, Casey C, Carroll RJ, et al. Developing Electronic Health Record Algorithms That Accurately Identify Patients With Systemic Lupus Erythematosus. Arthritis Care Res (Hoboken). 2017; 69: 687-93. 
10. Garris C, Jhingran P, Bass D, et al. Healthcare utilization and cost of systemic lupus erythematosus in a US managed care health plan. J Med Econ. 2013; 16: 667-77.

11. Kan H, Nagar S, Patel J, et al. Longitudinal Treatment Patterns and Associated Outcomes in Patients With Newly Diagnosed Systemic Lupus Erythematosus. Clin Ther. 2016; 38: 610-24.

12. Ke X, Eisenberg Lawrence DF, et al. Retrospective Administrative Claims Database Evaluation of the Utilization of Belimumab in US Managed Care Settings. Clin Ther. 2015; 37: 2852-63.

13. Moores KG and Sathe NA. A systematic review of validated methods for identifying systemic lupus erythematosus (SLE) using administrative or claims data. Vaccine. 2013; 31 Suppl 10: K62-73.

14. Gyori N, Giannakou I, Chatzidionysiou K, et al. Disease activity patterns over time in patients with SLE: analysis of the Hopkins Lupus Cohort. Lupus science \& medicine. 2017; 4: e000192.

\section{Tables}

Table 1. Estimated total number of prevalent SLE patients in the US, by major civilian health insurance, 2016

\begin{tabular}{|llll|}
\hline & Projection to Private insurance population & $\begin{array}{l}\text { Projection to Medicaid } \\
\text { population }\end{array}$ \\
\hline $\begin{array}{l}\text { Age } \\
\text { categories }\end{array}$ & $\begin{array}{l}\text { CCAE (age<65) and MDCR (age } \geq \\
65)^{1}\end{array}$ & $\begin{array}{l}\text { Optum (all } \\
\text { ages) }{ }^{2}\end{array}$ & \\
\hline$<18$ & & & MDCD $^{3}$ \\
\hline Female & 2,465 & 2,214 & 2,148 \\
\hline Male & 357 & 329 & 426 \\
\hline $18-64$ & & & 80,425 \\
\hline Female & 259,502 & 311,904 & 6,367 \\
\hline Male & 23,067 & 29,975 & 8,994 \\
\hline$\geq 65$ & & & 524 \\
\hline Female & 52,784 & 53,125 & 99,000 \\
\hline Male & 7,501 & 6,799 & \\
\hline $\begin{array}{l}\text { Total } \\
\text { (rounding) }\end{array}$ & 345,000 & 404,000 & \\
\hline
\end{tabular}

${ }^{1}$ based on estimated age, sex-specific prevalence proportion from CCAE (age <65) and MDCR (age $\left.\geq 65\right)$ multiplied by US census age and sex-specific counts of persons with private insurance in 2016; age 
categories were $<18,18-24,25-29,30-34,35-39,40-44,45-49,50-54,55-59,60-64$ in CCAE and 65-74, $\geq 75$ in MDCR.

2 based on estimated age, sex-specific prevalence proportion from Optum multiplied by US census age and sex-specific counts of persons with private insurance in 2016; age categories were <18, 18-24, 25-29, $30-34,35-39,40-44,45-49,50-54,55-59,60-64,65-74, \geq 75$ in Optum (separately done in those age $<65$ and age $\geq 65$ ).

${ }^{3}$ based on estimated age, sex-specific prevalence proportion from MDCD multiplied by US census age and sex-specific counts of persons with Medicaid insurance in 2016; age categories were $<18,18-24,25$ 29, 30-34, 35-39, 40-44, 45-49, 50-54, 55-59, 60-64, 65-74, $\geq 75$ in MDCD.

Table 2. Characterization of prevalent SLE patients and their healthcare utilization across 4 US databases, 2016 
CCAE MDCR OPTUM MDCD

\begin{tabular}{|c|c|c|c|c|}
\hline Total $\mathbf{N}$ & 28,846 & 4,281 & 23,877 & 15,096 \\
\hline Women, n (\%) & $\begin{array}{l}26,476 \\
(91.8)\end{array}$ & $\begin{array}{l}3,759 \\
(87.8)\end{array}$ & $\begin{array}{l}21,568 \\
(90.3)\end{array}$ & $\begin{array}{l}13,979 \\
(92.6)\end{array}$ \\
\hline Mean age $(S D)$, years & $47(12)$ & $72(7)$ & $56(15)$ & $45(15)$ \\
\hline \multicolumn{5}{|l|}{ Number of visits, median (interquartile range) } \\
\hline for any healthcare encounter & $17(10-30)$ & $\begin{array}{l}25(15- \\
41)\end{array}$ & $20(11-35)$ & $25(13-49)$ \\
\hline with an SLE diagnosis & $4(2-7)$ & $3(2-5)$ & $4(2-7)$ & $4(2-8)$ \\
\hline $\begin{array}{l}\text { Number of patients with } \geq 1 \text { hospitalization, } n \\
(\%)\end{array}$ & $\begin{array}{l}4,374 \\
(15.2)\end{array}$ & $\begin{array}{l}1,185 \\
(27.7)\end{array}$ & $\begin{array}{l}4,510 \\
(18.9)\end{array}$ & $\begin{array}{l}5,044 \\
(33.4)\end{array}$ \\
\hline $\begin{array}{l}\text { Median (interquartile range) length of hospital- } \\
\text { stay, days }\end{array}$ & $3(2-6)$ & $4(2-8)$ & $4(2-6)$ & $4(2-6)$ \\
\hline \multicolumn{5}{|l|}{ Co-morbidities*, n (\%) } \\
\hline Renal diseases & $\begin{array}{l}5,018 \\
(17.4)\end{array}$ & $\begin{array}{l}1,177 \\
(27.5)\end{array}$ & $\begin{array}{l}6,089 \\
(25.5)\end{array}$ & $\begin{array}{l}4,328 \\
(28.7)\end{array}$ \\
\hline Renal dialysis/failure & $\begin{array}{l}2,429 \\
(8.4)\end{array}$ & $\begin{array}{l}902 \\
(21.1)\end{array}$ & $\begin{array}{l}3,970 \\
(16.6)\end{array}$ & $\begin{array}{l}2,781 \\
(18.4)\end{array}$ \\
\hline \multicolumn{5}{|l|}{ Cardiovascular diseases } \\
\hline Hypertension & $\begin{array}{l}10,191 \\
(35.3)\end{array}$ & $\begin{array}{l}2,999 \\
(70.1)\end{array}$ & $\begin{array}{l}11,457 \\
(48.0)\end{array}$ & $\begin{array}{l}5,218 \\
(34.6)\end{array}$ \\
\hline Ischemic heart disease & $\begin{array}{l}1,031 \\
(3.6)\end{array}$ & $\begin{array}{l}545 \\
(12.7)\end{array}$ & $\begin{array}{l}2,186 \\
(9.2)\end{array}$ & $1,433(9.5)$ \\
\hline Heart failure & $903(3.1)$ & $\begin{array}{l}638 \\
(14.9)\end{array}$ & $\begin{array}{l}2,275 \\
(9.5)\end{array}$ & $\begin{array}{l}2,047 \\
(13.6)\end{array}$ \\
\hline Rheumatic heart disease & $483(1.7)$ & $236(5.5)$ & $799(3.4)$ & $537(3.6)$ \\
\hline Cerebral vascular diseases & $\begin{array}{l}1,052 \\
(3.7)\end{array}$ & $\begin{array}{l}484 \\
(11.3)\end{array}$ & $\begin{array}{l}1,747 \\
(7.3)\end{array}$ & $1,409(9.3)$ \\
\hline
\end{tabular}

Neuropsychiatric conditions

Headache (recorded on claims)

\begin{tabular}{|c|c|c|c|}
\hline $\begin{array}{l}4,043 \\
(14.0)\end{array}$ & $\begin{array}{l}512 \\
(12.0)\end{array}$ & $\begin{array}{l}3,804 \\
(15.9)\end{array}$ & $\begin{array}{l}3,897 \\
(25.8)\end{array}$ \\
\hline $444(1.5)$ & $272(6.4)$ & $990(4.2)$ & $1,004(6.7)$ \\
\hline $\begin{array}{l}1,050 \\
(3.6)\end{array}$ & $144(3.4)$ & $\begin{array}{l}1,336 \\
(5.6)\end{array}$ & $\begin{array}{l}1,800 \\
(11.9)\end{array}$ \\
\hline $\begin{array}{l}4,112 \\
(14.3)\end{array}$ & $\begin{array}{l}698 \\
(16.3)\end{array}$ & $\begin{array}{l}4,782 \\
(20.0)\end{array}$ & $\begin{array}{l}3,284 \\
(21.8)\end{array}$ \\
\hline
\end{tabular}


CCAE MDCR OPTUM MDCD

\begin{tabular}{lllll}
\hline Total N & $\mathbf{2 8 , 8 4 6}$ & $\mathbf{4 , 2 8 1}$ & $\mathbf{2 3 , 8 7 7}$ & $\mathbf{1 5 , 0 9 6}$ \\
\hline Cutaneous manifestations & & & & \\
\hline Cutaneous lupus & 4,452 & 683 & 4,133 & 3,136 \\
& $(15.4)$ & $(16.0)$ & $(17.3)$ & $(20.8)$ \\
\hline Dermatosis and dermatitis & 3,977 & 683 & 3,412 & 2,184 \\
& $(13.8)$ & $(16.0)$ & $(14.3)$ & $(14.5)$ \\
\hline Infections & 8,778 & 1,450 & 7,955 & 6,405 \\
& $(30.4)$ & $(33.9)$ & $(33.3)$ & $(42.4)$ \\
\hline Hospitalized infections & 1,543 & 472 & 1,847 & 2,168 \\
& $(5.4)$ & $(11.0)$ & $(7.7)$ & $(14.4)$ \\
\hline Musculoskeletal comorbidities & & & & \\
\hline Inflammatory Polyarthropathies & & & & 3,688 \\
& $(23.3)$ & $(28.9)$ & $(31.0)$ & $(24.4)$ \\
\hline Spondylopathies & 3,050 & 874 & 3,999 & 2,337 \\
& $(10.6)$ & $(20.4)$ & $(16.8)$ & $(15.5)$ \\
\hline Osteoarthritis & 7,257 & 2,251 & 9,360 & 5,145 \\
& $(25.2)$ & $(52.6)$ & $(39.2)$ & $(34.1)$ \\
\hline Osteoporosis & 2,351 & 1,056 & 4,051 & $1,257(8.3)$ \\
& $(8.2)$ & $(24.7)$ & $(17.0)$ & \\
\hline
\end{tabular}

Medication** use (any), n (\%)

\begin{tabular}{lllll}
\hline Anti-malarials & $\begin{array}{l}18,129 \\
(62.8)\end{array}$ & $\begin{array}{l}2,275 \\
(53.1)\end{array}$ & $\begin{array}{l}12,411 \\
(52.0)\end{array}$ & $\begin{array}{l}5,324 \\
(35.3)\end{array}$ \\
\hline Systemic corticosteroids & $\begin{array}{l}18,518 \\
\text { (64.2) }\end{array}$ & $\begin{array}{l}2,768 \\
(64.7)\end{array}$ & $\begin{array}{l}14,619 \\
(61.2)\end{array}$ & $\begin{array}{l}9,255 \\
(61.3)\end{array}$ \\
\hline Non-biologic disease modifying drugs & 5,906 & 660 & 3,904 & 2,423 \\
& $(20.5)$ & $(15.4)$ & $(16.4)$ & $(16.1)$ \\
\hline Biologics & 1,286 & $139(3.2)$ & $818(3.4)$ & $480(3.2)$ \\
& $(4.5)$ & & & \\
\hline Any of the above & 25,037 & 3,620 & 19,268 & 10,746 \\
& $(86.8)$ & $(84.6)$ & $(80.7)$ & $(71.2)$
\end{tabular}

${ }^{\dagger}$ Physician specialty is incompletely captured or unspecified in insurance claims databases, especially MDCD.

* Based on diagnosis codes, except for depression which includes anti-depressant prescriptions (codes provided in the online supplemental materials). 
** Anti-malarials included artemether, lumefantrine, atovaquone, proguanil, chloroquine, halofantrine, hydroxychloroquine, mefloquine, primaquine, pyrimethamine, quinacrine, quinine, sulfadoxine, pyrimethamine, chloroquine; Non-biologic disease modifying drugs included azathioprine, chlorambucil, cyclophosphamide, cyclosporine, methotrexate, mycophenolate mofetil, mycophenolic acid; Biologics included abatacept, rituximab, tocilizumab, adalimumab, etanercept, infliximab, golimumab, certolizumab pegol, ustekinumab, secukinumab, ixekizumab, vedolizumab, belimumab

\section{Figures}

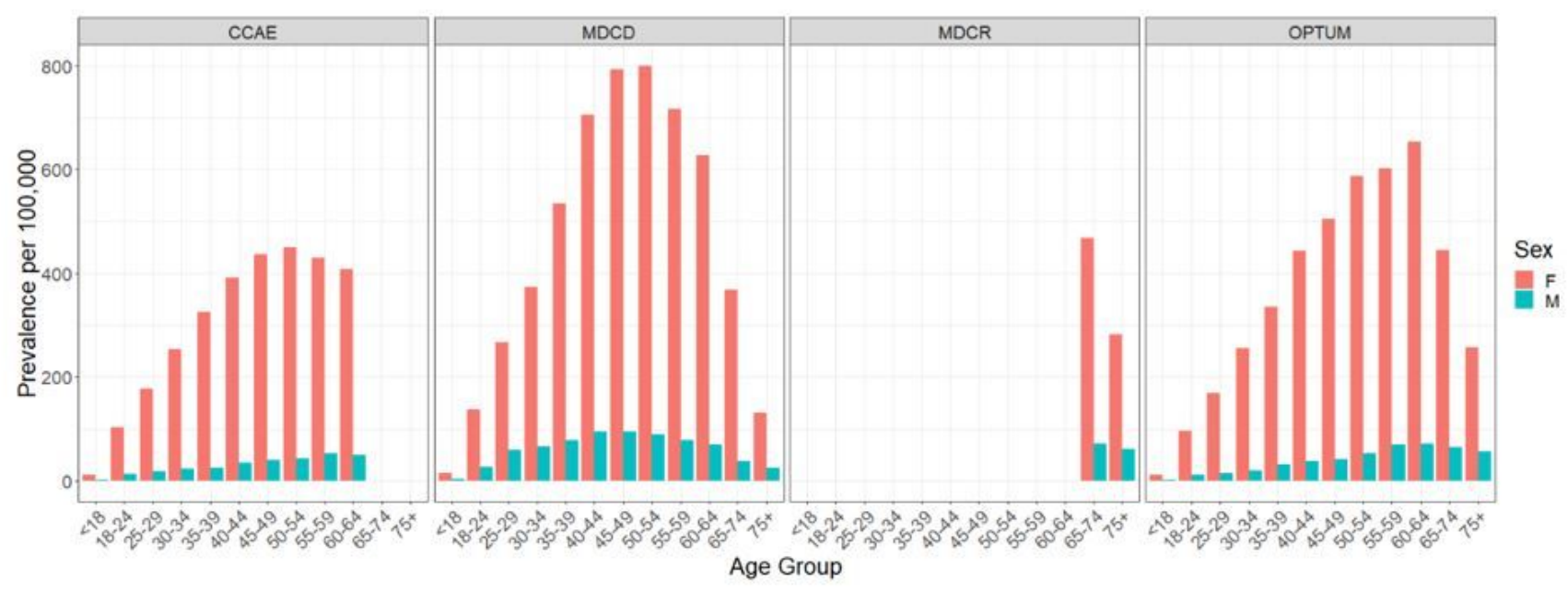

Note, see Supplemental Digital Content Supplemental Figure 1 for prevalence proportions under age 65 for MDCR.

\section{Figure 1}

Age-, and sex-specific prevalence of SLE in the 4 study databases, 2016

\section{Supplementary Files}

This is a list of supplementary files associated with this preprint. Click to download.

- SuppMaterialBMCReserachNotesSLEPrevalence.docx 